\title{
A Call to Action
}

Project management is a mature discipline, supported by professional bodies, standards, extensive training resources and a huge literature. The same can increasingly be said for the newer, related disciplines of change management, programme management and portfolio management. One mark of their maturity is that component parts of these disciplines have become respected specialisms in their own right: estimating, planning and scheduling, resource management and risk management. In each of these areas, project managers have built up significant bodies of knowledge and toolsets, to the extent that experts can specialise and call themselves planners, resource managers and risk managers. I would like to see stakeholder engagement management join these specialisms. Like them, it is a crucial part of the success of any project or programme, there is a body of techniques and tools to learn and deploy, and it requires experience, skills and knowledge to do well.

Whether you share this ambition or not, what matters are the results you get and how you get them. I would like to see the methods and tools of stakeholder engagement become more than a short chapter in a project management book or a single exercise in a two-day training programme. I hope this book has shown you that there is more than enough material to allow project stakeholder engagement management to stand alone as a discipline with its own literature and toolset. And if it has, I would like to think that I have gone some way to creating a wider culture of effective and ethical stakeholder engagement within projects and programmes of change.

To everyone who aspires to engage respectfully with your stakeholders, or to manage that process, good luck.

Mike Clayton, March 2014 